DOI: $\underline{\text { https://doi.org/10.24867/14GI01Kracunovic }}$

\title{
UNAPREĐENJE PROCESA TRANSPORTA U PREDUZEĆU INVENT" D.O.O RAKOVAC
}

\section{IMPROVING OF TRANSPORT PROCESS IN INVENT" COMPANY}

\author{
Nina Kračunović, Fakultet tehničkih nauka, Novi Sad
}

\section{Oblast - INDUSTRIJSKO INŽENJERSTVO}

Kratak sadržaj - U radu je prikazan značaj logistike, a posebna pažnja je stavljena na proces transporta. Dat je predlog unapređenja procesa transporta u preduzeću „Invent" d.o.o. Rakovac.

Ključne reči: Logistika, transport, analiza stanja, mere unapređenja

Abstract - This paper describes importance of logistics for the organisation. Emphasis is placed on the major subsystems of logistics. It is proposed the improvement of transport process in ,Invent" company.

Keywords: Logistics, transport, Analysis of the situation, Measures for improvements

\section{UVOD}

Od svog nastanka pa do danas, logistika se razvila $u$ savremenu naučnu disciplinu, sa kojom se u teoriji i praksi upravlja sistemima i procesima. Njena specifična funkcija u okviru organizacionih, društvenih i drugih sistema, podrazumeva proces planiranja i obezbeđenja dobara i usluga radi zadovoljenja potreba posmatranog sistema.

Transportne usluge imaju strategijsku ulogu i primarni značaj u primeni logistike (koja ima cilj da optimizuje kretanje tereta, odnosno da poveća efikasnost transportnih tokova, preko smanjenja troškova i većeg zadovoljenje korisnika transportnih usluga). Transport je samostalna privredna delatnost koja se bavi prenosom materijalnih dobara, ljudi i vesti, sa jednog mesta na drugo, u cilju zadovoljenja ljudskih potreba, kako u sferi materijalne proizvodnje, tako i u svakodnevnom životu.

U prvom delu rada govori se o pojmu,značaju i podeli logistike. Takođe će biti opisan i istorijski razvoj logistike, koji su zadaci logistike i značaj transporta u logistici. U nastavku rada objašnjen je proces transporta, koji sve vidovi transporta postoje, značaj integralnog transporta i razlika između spoljašnjeg i unutrašnjeg transporta. Nakon toga, u radu se govori o poslovanju preduzeća "Invent" d.o.o. Rakovac, kao i o načinu transporta u samom preduzeću. Dalje su prikazane metode za analizu stanje procesa transporta u samom preduzeću, poput SWOT analize, kao i Ishikawa dijagrama. Na taj način su uočeni određeni nedostaci prilikom procesa transporta, nakon čega su predložene određene mere unapređenja.

\section{NAPOMENA:}

Ovaj rad proistekao je iz master rada čiji mentor je bio dr Stevan Milisavljević, vanr. prof.

\section{TEORIJSKE OSNOVE}

\subsection{Pojam i značaj logistike}

Sama reč logistika postoji u svim osnovnim evropskim jezicima, ali ima različita značenja. Izraz logistika u evropskim jezicima je u proteklom periodu imao dva različita značenja, i to:

- matematička logika,

- tehnika i tehnologija transportno-pretovarnoskladišnih procesa u privrednoj i/ili vojnoj oblasti [1].

Faze razvoja logistike:

1. Do 1960. godine- kapacitet proizvodnje maksimalno iskorišćen, logistika, kao posebna prvi put je uvedena pedesetih godina, po celoj kompaniji.

2. Od 1960. do 1970. godine- unapređenje prodaje i marketinga, nije se dovoljno vodilo računa o finansijskom trošku zaliha, sve veće interesovanje za vreme isporuke, način isporuke i stepen raspoloživosti.

3. Posle 1980. godine- značajne rezerve racionalizacije, logistika postaje konkurentsko oružje, proširenje na različita tržišta, porast potreba za koordinacijom i kontrolom kretanja svih materijalnih i robnih tokova [2].

\subsection{Zadaci logistike}

Zadaci logistike mogu se podeliti na sledeće komponente: tehničku komponentu, ekonomsku ili vrednosnu komponentu, informacionu komponentu, kvalitativnu komponentu, vremensku komponentu, komponentu racionalnog korišćenja resursa.

\subsection{Značaj transporta u logistici}

Funkcija transport se bavi kretanjem robe od jedne ekonomske strane do druge ekonomske strane.

Proces transporta predstavlja produžetak procesa proizvodnje. Njima se dopremaju sirovine i pomoćni materijali do mesta prerade, zatim se vrši premeštanje dobara u samoj proizvodnji da bi se na kraju gotovi proizvodi i poluproizvodi raznim saobraćajnim sredstvima dovezli do tržišta. Transportom se osigurava i radna snaga za sve društvene i privredne delatnosti i kretanje stanovništva iz jednog mesta u drugo, iz bilo kojih razloga. Zato se transport izdvaja u posebnu delatnost materijalne proizvodnje koja se naziva transportna industrija. Transport je podsistem sistema logistike, najvažniji segment logističkog segmenta na nivou preduzeća. 


\subsection{Transport i vrste transporta}

Naziv je nastao od latinske reči transportus, može se reći da reč transport u suštini znači prenošenje ili prevoženje putnika i robe. To podrazumeva da transport predstavlja prevoz robe ili putnika između drumskih i železničkih stanica, aerodroma ili luka i međusobno. Transport kao deo privrede predstavlja, u suštini skup saobraćajnih sredstava i puteva, kao i pratećih sistema, opreme i uređaja neophodnih za nesmetano odvijanje procesa transporta [3].

Za prevoz robe na raspolaganju stoji više nosilaca transporta: drumski transport, železnički transport, vodni transport, vazdušni transport, cevni transport kombinovani transport.

\section{O PREDUZEĆU}

Preduzeće Invent d.o.o. Rakovac osnovano je 1986. godine i trenutno broji 20 zaposlenih. U proizvodni program preduzeća "INVENT" d.o.o Rakovac spadaju: Vodokotlići, kuhinjski bojleri, protočni bojler sa slavinom, toaletni poklopci, inteligentni elastični sifoni, kombinovani sifoni, cevi i fazonski komadi, rezervni delovi [4].

\subsection{Transport u preduzeću "Invent" d.o.o. Rakovac}

Preduzeće "Invent" d.o.o. Rakovac svoje proizvode isporučuje na teritorije cele Srbije, a najviše u tri regije u Vojvodini i to : južno-bački, sremski, zapadno- bački .

$\mathrm{Za}$ potrebe transporta, preduzeće raspolaže sa tri sopstvena vozila $\mathrm{u}$ voznom parku, i to: VW Polo,Mercedes sprinter kombi i VW Cady.

Transport se vrši tri puta nedeljno,kada je vozilo punog kapaciteta. Od vidova transporta, u ovom preduzeću koristi se isključivo drumski. Uvoz delova neophodnih za prozvodnju iz inostranstva se vrši pomoću kontejnerskog transporta, uz pomoć špediterskih firmi.

$\mathrm{Za}$ potrebe transporta zaposlen je samo jedan profesionalni vozač, a ukoliko ima potrebe, transport obavlja i magacioner. Vozač vrši prevoz svih dobara za potrebe preduzeća, vrši prevoz lica za potrebe preduzeća, stara se o tehničkoj ispravnosti vozila i blagovremeno vrši tehnički pregled vozila u skladu sa propisima kod ovlašćenog servisera.

U preduzeću ne postoji posebna služba koja se bavi transportom, već poslove oko organizacije transporta vrši komercijalista.

\subsection{Metode za analizu stanja u preduzeću „Invent" d.o.o. Rakovac SWOT analiza}

SWOT analiza je tehnika strategijskog menadžmenta putem koje se uočavaju strategijski izbori dovođenjem u vezu snaga i slabosti preduzeća sa šansama i pretnjama u eksternom okruženju.

Ona predstavlja alat za upoznavanje situacije u preduzeću ili odeljenju [5].

Sprovedena je SWOT analiza u preduzeću „Invent" d.o.o. Rakovac.
Snage:

1. Kvalitet proizvoda

2. Povoljne cene proizvoda

3. Dobar digitalni marketing (e- mail,web sajt gde se mogu dobiti sve informacije)

4. Finansijski potencijal preduzeća

5. Dobra obučenost kadrova

Mogućnosti:

1. Uvođenje online prodaje

2. Povećanje profita preduzeća povećanjem efikasnosti i obima posla

3. Otvaranje novih maloprodajnih objekata

Slabosti:

1. Nedovoljan broj profesionalnih vozača

2. Nepostojanje GPS sistema u vozilima

3. Neredovno održavanje voznog parka

4. Slab kadrovski potencijal u delu prodaje

Pretnje:

1. Nepoštovanje dogovorene saradnje od strane poslovnog partnera u inostranstvu

2. Jaka konkurencija

3. Ekonomska kriza, koja bi uslovila rast cena sirovina

$\mathrm{Na}$ osnovu prikazanih snaga, slabosti, šansi i pretnji preduzeće "Invent" d.o.o. Rakovac treba da definiše poslovnu strategiju. Potrebno je da se minimiziraju slabosti i pretnje, a da se maksimiziraju snage i iskoriste šanse.

\section{ISHIKAWA dijagram}

Ishikawa dijagram predstavlja jednostavnu i vrlo korisnu metodu za sagledavanje što više mogućih uzroka koji dovode do posledice/problema koji se analizira. Analiza UZROK-POSLEDICA zasniva se na principu uzročnosti. Uzročnost je odnos između jednog događaja (uzrok) i drugog događaja (efekat), gde se drugi događaj shvata kao posledica prvog.

Vizuelni prikaz uzroka koji ova metoda pruža odgovara izgledu riblje kosti, pa se otuda ovaj dijagram često naziva riblja kost (Fishbone diagram).

Najčešći uzroci koji dovode do nastanka problema prilikom transporta su:

- nekompletni papiri,

- nečitka i nejasna dokumentacija,

- neredovno održavanje vozila,

- izostanak najave špedicije,

- neoverena dokumenta,

- nepovoljni vremenski uslovi,

- $\quad$ kašnjenje u isporuci,

- nalog za transport,

- poplave, zemljotresi,

- nedostatak vozača,

- pogrešno ispunjena dokumentacija,

- pregled robe,

- nedostatak goriva,

- gužva u saobraćaju, 
- kvar na vozilu,

- greška komercijaliste.

Klasifikacija uzroka

1. Ljudski faktor

U ovu grupu spadaju uzroci koji dovode do problema prilikom transporta, a uslovljeni su ljudskom greškom. U ovu grupu spadaju: izostanak najave špedicije, greška komercijaliste, pregled robe .

\section{Dokumentacija}

Jedan od najznačajnijih i najčešćih uzroka koji može da oteža i onemogući transport je dokumentacija. U ove uzroke se ubrajaju:

neoverena dokumenta, nekompletni papiri, pogrešno ispunjena dokumentacija, nalog za transport.

\section{Prirodne nepogode}

Ovu grupu uzroka nije moguće kontrolisati niti sprečiti. U ove uzroke se ubrajaju:

nepovoljni vremenski uslovi (sneg, mećava), poplave, zemljotresi , gužva u saobraćaju.

\section{Tehnički otkazi}

U grupu tehničkih otkaza spadaju uzroci:

neredovno održavanje vozila, nedostatak vozača, nedostatak goriva, kvar na vozilu.

$\mathrm{Na}$ Ishikawa dijagramu su prikazani svi uzroci koji dovede do problema $u$ transportu. Pomoću ovog dijagrama je moguće sagledati sve uzroke koji deluju na dati problem. Takođe, nakon crtanja Ishikawa dijagrama nije moguće rešiti dati problem, već je ovaj dijagram dobra podloga za sagledavanje svih uzroka problema i na osnovu njega se mogu doneti bitne odluke, nakon kojih će se uz pomoć drugih metoda pronaći rešenje za dati problem.

\section{MERE UNAPREĐENJA UOČENOG NEDOSTATKA}

$\mathrm{Na}$ osnovu analize obavljanja procesa transporta u preduzeću "Invent" d.o.o. Rakovac, utvrđen je nedostatak. Preduzeće nema ugrađen GPS sistem u vozila, ima samo jednog profesionalnog vozača i vozni park je nedovoljno održavan.

Mere unapređenja procesa transporta $\mathrm{u}$ preduzeću "Invent" d.o.o. Rakovac su:

1. Uvođenje GPS sistema u vozila

2. Kupovina kamiona

3. Kombinovanjem sopstvenog i outsourcing transporta

\subsection{Uvođenje GPS sistema u vozila}

GPS (Global Positioning System) uređaji za praćenje se koriste u svim vrstama transportne delatnosti, od putničkog i teretnog programa, preko radnih i poljoprivrednih mašina do plovila. Sam princip rada ovakvog sistema podrazumeva da je satelit $u$ komunikaciji sa trekerom $\mathrm{u}$ vozilu, treker prikuplja informacije od satelita i preko mobilne telefonije i mobilnog interneta, šalje podatke $u$ data centar kojem može da se pristupi sa bilo kog uređaja koji može da izađe na internet. Ovakav vid unapređenja bi doneo brojne pogodnosti za preduzeće. Na ovaj način bi se poboljšalo poslovanje samog preduzeća, što bi uslovilo i bolje pozicioniranje na tržištu. Takođe, sama isporuku i kretanje vozila bi mogla da se prati i preko mobilnih uređaja. Smanjio bi se rizik od krađa transportnih vozila, kao i smanjenje rizika po bezbednosti robe koja se prevozi.

Preduzeće bi korišćenjem ovakvog sistema nakon prva tri meseca napravila uštedu od $10 \%$ do $30 \%$. Za izbor kompanije koja bi izvršila ugrađu GPS sistema, formirana komisija iz komercijalnog sektora bi izabrala kompaniju sa najpovoljnijom ponudom.

Finansijski trošak koji bi preduzeće trebalo da uloži u ovakav sistem bi iznosio $225 €$ za sva tri vozila. U ponudi su dva načina plaćanja, kupovina uređaja i najam. Ugovor sa kompanijom se potpisuje na period od 12 meseci. Ovakve kompanije omogućavaju zainteresovanim klijentima da testiraju mogućnosti sistema za satelitsko praćenje vozila. U periodu od 30 dana klijenti se mogu upoznati sa funkcijama GPS sistema, načinom rada i uštedom koja se ostvaruje korišćenjem sistema praćenja.

\subsection{Kupovina kamiona}

Kupovina kamiona bi preduzeću omogućila da poboljša drumski vid transporta,kao i to što bi se, u izvesnom vremenskom periodu smanjili troškovi u kompaniji, unapredilo poslovanje, bilo bi znatno efikasnije i brže poslovanje, što je veoma bitno danas, kada se sve radi brzo i efikasno.Na ovaj način bi se povećali postojeći kapaciteti preduzeća, čime se omogućuje prisutnost na više destinacija i većem broju tržišta.

Cena pomenutog vozila se kreće od 5 do 10 hiljada evra za mali kamion, te je neophodno da preduzeće podigne kredit $\mathrm{u}$ datom iznosu na period od 5 do 10 godina. $\mathrm{S}$ obzirom da se radi o ulaganju u opremu, tip kredita koji bi bio podignut je dugoročni investicioni kredit.

Takođe, postoji opcija lizinga. Lizing je finansiranje kupovine sa pravom korišćenja predmeta lizinga do isteka ugovora. Pravo svojine prenosi se na korisnika lizinga po isplati poslednje rate $\mathrm{i}$ svih drugih obaveza po osnovu ugovora.

Prikazom dva načina finansiranja vozila, putem kredita i lizinga na isti vremenski period, uočava se da je mesečna rata koju je potrebno izdvojiti u slučaju lizinga $12.23 €$ viša od one u slučaju kredita, međutim kod kredita je neophodno izdvojiti inicijalno učešće u visini od $20 \%$ investicije, odnosno $2000 €$, što za preduzeće predstavlja finansijski izdatak, u odnosu na $1000 €$, koliko je potrebno za učešće u slučaju lizinga.

\subsection{Kombinovanje sopstvenog i outsourcing transporta}

Outsourcing predstavlja saradnju između kompanija i pojedinaca, sa time da je jedna od dve kompanije (odnosno pojedinac) u ulozi izvođača, dok je druga $u$ ulozi poslodavca. 
Drugim rečima, jedna kompanija ili pojedinac drugoj kompaniji pruža svoje usluge.

Preduzeće bi u ovom slučaju raspisalo konkurs za izbor najoptimalnije kompanije za prevoz robe. Odabrala bi se kompanija sa najpovoljnijom ponudom u smislu cene, efikasnosti, kvaliteta usluge, spremnosti za isporuku i slično. Oformila bi se komisija unutar komercijalne službe, koja bi razmatrala odgovarajuće ponude kompanija i na kraju donela odluku sa kojim prevoznikom će se sklopiti ugovor o vršenju usluge transporta na određeni vremenski period.

Uvođenje kombinacije sopstvenog i outsourcing transporta se zasniva na mogućnosti podele sopstvenog transporta. Podela transporta mogla bi se vršiti tako da preduzeće "Invent" d.o.o. Rakovac, sopstvenim prevozom vrši dva puta nedeljno transport robe, dok bi se transport jedanput nedeljno, na dalje lokacije, vršio angažovanjem outsourcing kompanije. U slučaju hitnih intervencija, kao i iznenadne bolesti samog vozača, transport robe bi obavljala angažovana kompanija.

Među najznačajnim firmama koje se bave outsourcing ransportom nalaze se City Express d.o.o., Ralu Beograd.o d.o.o., DSD Euroline d.o.o., Farmalogist, AKS, Post Express, Bobak itd.

Na osnovu urađene troškovne analize u kojoj smo posmatrali ukupne godišnje troškove angažovanjem sopstvenog vozila i transport u kombinaciji sa angažovanjem outsourcing kompanije, pod pretpostavkom da bi ista vršila transport sa udelom od 1/3 ukupne godišnje kilometraže. $\mathrm{Na}$ osnovu toga, dolazimo do zaključka da bi preduzeće „INVENT” d.o.o. Rakovac, uštedelo primenom ovog predloga unapređenja 1.030.600 dinara na godišnjem nivou, odnosno 85.883 dinara mesečno.

Samim tim, kompanija bi poboljšala svoje poslovanje, pri čemu bi došlo do smanjenja troškova, što rezultira velikom izboru mogućnosti ulaganja $u$ dalji razvoj kompanije.

\section{ZAKLJUČAK}

Logistika je veoma stara oblast koja se razvijala i usavršavala paralelno sa razvojem civilizacije. Logistika je interdisciplinarna oblast sistema koji obuhvata resurse, procese, infrastrukturu, ali i ekonomsku podršku vezanu za realizaciju postavljenih ciljeva tokom životnog ciklusa proizvoda.

U prvom delu rada opisan je sam pojam i značenje pojma logistike, kao i definicije logistike. Nakon toga je istaknuto koji su zadaci logistike, kao i značaj koji transport ima u logistici. U drugom delu rada prikazano je koji parametri utiču na izbor vidova transporta, koje su karakteristike i izbor prevoznika i koje vrste transporta postoje.
Glavni deo rada se odnosi na snimak stanja i načina poslovanja preduzeća „Invent" d.o.o. Rakovac, koje se bavi proizvodnjom sanitarne opreme. Odnosno, prikazano je koji sve vidovi transporta postoje u preduzeću, kako se obavlja sam način transporta i koje vidove transporta preduzeće najviše koristi. Urađena je SWOT analiza, kako bi se videlo koje su snage, slabosti, šanse i pretnje ovog preduzeća. Nakon toga je izvršena analiza uz pomoć Ishikawa dijagrama, gde je grafički prikazano koji uzroci najčešce dovode do problema u transportu.

Zatim je obradom internih podataka preduzeća utvrđeno koji su određeni nedostaci, kao što su nedostatak GPS sistema, slaba tehnička opremljenost voznog parka i nedovoljan broj vozača i nakon toga je dat predlog mera unapređenja kako samog procesa transporta, tako i celokupnog poslovanja ove kompanije. Navedene mere bi obezbedile bolju organizaciju, planiranje i upravljanje transportom a što bi dovelo do boljeg poslovanja preduzeća.

\section{LITERATURA}

[1] Prof. dr Dušan Regodić (2011), „, Logistika", Beograd

[2] Avlijaš, G. Razvoj i pojam logistike, Univerzitet Sinergija

[3 ] Prof. dr Miodrag Bulatović (2013), ,,Logistika", Podgorica

[4] http://www.invent.co.rs/ Pristup: 15.09.2019.

[5] D. Stanivuković, Metode i tehnike unapređenja procesa rada, Fakultet tehničkih nauka, Novi Sad, 2002.

\section{Kratka biografija:}

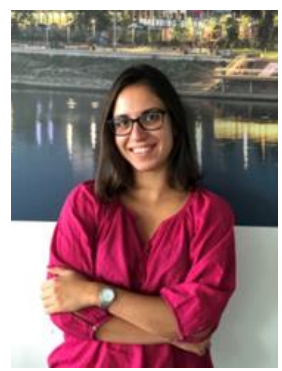

Nina Kračunović rođena je u Novom Sadu 13.11.1996. godine. Master rad na Fakultetu tehničkih nauka iz oblasti Industrijsko inženjerstvo - Unapređenje procesa transporta $\mathrm{u}$ preduzeću „Invent" d.o.o, Rakovac, odbranila je 2021. godine.

Kontakt: nina13ftn@gmail.com 